\title{
Rotator manşet rüptürünün nadir bir nedeni: Subakromial osteokondrom
}

An uncommon cause of rotator cuff rupture: Subacromial osteochondroma

\author{
Mesut Tahta Eyüp Çağatay Zengin Tuğrul Bulut Cihan Aslan Muhittin Şener
}

Katip Çelebi Üniversitesi, İzmir Atatürk Eğitim Araştırma Hastanesi, Ortopedi ve Travmatoloji Kliniği,

İzmir, Türkiye

\section{Öz}

Osteokondrom, sık görülen ve genellikle uzun kemiklerin metafizyel bölgelerinde gelişen benign bir kemik tümörüdür. Skapular tutulum ise nadirdir. Bu çalışmada, 1 yıldır devam eden omuz ağrısı ile gelen 66 yaşında kadın hasta sunulmuştur. Hastanın omuz eklemi hareket açıklığında, özellikle abduksiyonda azalma mevcuttu. Direkt grafi, BT ve MRG ile değerlendirilen hastada rotator manşet rupture ile birlikte subakromial osteokondrom tespit edildi. Transakromial mini açık insizyonla osteokondrom total eksize edilip rotator manşet onarıldı. Ameliyat sonrası 19. ayda, hastanın omuz eklem hareketleri ağrısız ve eklem hareket açıklığı artmıştı. Subakromial bölgede nadir görülmesine rağmen osteokondrom, rotator manşet rüptürüne sebep olabilir. Tedavide gecikme olması halinde ilgili yırtığın genişleyebileceği unutulmamalı, erken eksizyonun önemi göz önünde bulundurulmalıdır.

Anahtar Sözcükler: Rotator manşet rüptürü, osteokondrom, omuz, akromion.

\section{Abstract}

Osteochondroma is frequently seen benign bone tumour and generally develops in the metaphyseal sections of long bones. Scapular involvement is rare. In this paper, a 66-year old female is presented with shoulder pain which had been ongoing for 1 year. The range of movement of the shoulder joint had decreased. Shoulder abduction was especially painful. From examinations of direct radiographs, CT and MRI, rotator cuff rupture was determined associated with subacromial osteochondroma. With a transacromial approach, the osteochondroma was excised and the cuff was repaired. At postoperative 19th month, the patient had a pain-free shoulder with increased range of motion. Although rarely seen in the subacromial region, osteochondroma may cause a rotator cuff rupture. It must not be forgotten that if treatment is delayed the tear will widen, and the importance of early excision should be kept in mind.

Keywords: Rotator cuff rupture, osteochondroma, shoulder, acromion.

\section{Giriş}

Rotator manşet rüptürü, genellikle orta ve ileri yaşta görülen, ana semptomları ağrı ve eklem hareket açıklığında azalma olan, sık görülen bir dejeneratif tendon yaralanması olup nadiren travmaya bağlıdır (1). Genellikle anterolateral akromion ventral yüzü, korakoakromial ligaman ya da distal klavikulanın ventral yüzünün neden olduğu mekanik irritasyon sonucu oluşur (2). Öte yandan osteokondroma, non-ossifiye fibromu takip eden en sık görülen ikinci benign kemik tümörüdür ve sıklıkla uzun kemiklerin metafizyel kısımlarında gelişir (3). Skapula tutulumu ise nadir olup \%3-4 civarındadır (4). Böyle bir tablo nadir de olsa rotator manşet rüptürüne sebep olabilir ve bu durum, literatürde sınırlı sayıda bildirilmiştir (5).

\footnotetext{
Yazışma Adresi: Mesut Tahta

Katip Çelebi Üniversitesi, İzmir Atatürk Eğitim Araştırma Hastanesi, Ortopedi ve Travmatoloji Kliniği, İzmir, Türkiye
}

Makalenin Geliş Tarihi: 02.11.2016 Kabul Tarihi: 14.12.2016
Bu çalışmada subakromial bölgede inmal edilmiş geniş çaplı osteokondroma bağlı oluşan rotator manşet rüptürünü sunmayı amaçladık.

\section{Olgu Sunumu}

Altmış altı yaşında ev hanımı olan kadın hasta, sol omzunda yaklaşık 1 yıldır devam eden ağrı ve son 6 ayda artan hareket kısıtııı̆ı şikayeti ile başvurdu. Daha önce başka bir merkezde çeşitli medikal tedaviler ve fizik tedavi gördüğünü ancak şikayetlerinde herhangi bir gerileme olmadığını bildirmekteydi. Hastadan daha önce grafi istenmemiş. Yakın zamanlı travma öyküsü de bulunmamaktaydı. Gece terlemeleri ve yakın zamanda belirgin kilo kaybı olmamıştı ve ailesinde kanser öyküsü bulunmamaktaydı. Boyu $1.63 \mathrm{~m}$, kilosu 88 kg, vücut kitle indeksi 33.1 idi. Omuzunda ısı artışı, kızarıklık yoktu ve nörovasküler muayenesi doğaldı. Dışarıdan gözle görülür bir deformitesi yoktu. Omuz aktif abduksiyonu yaklaşık 70 dereceye kadardı, fleksiyon 90 derece, dış rotasyon 30 derece ve 10 dereceden daha az iç rotasyon mevcuttu. Neer ve Hawkins testleri pozitif 
olarak değerlendirildi. Omuzda instabilite bulgusu yoktu. Hastanın diğer bölgelerinde benzer şikayeti ve anlamlı fizik muayene bulgusu yoktu. Direkt radyografide subakromial bölgede akromiona bağlı halde kemik dansitesinde kitle görülen hastaya BT ve MRG çekildi (Şekil-1).

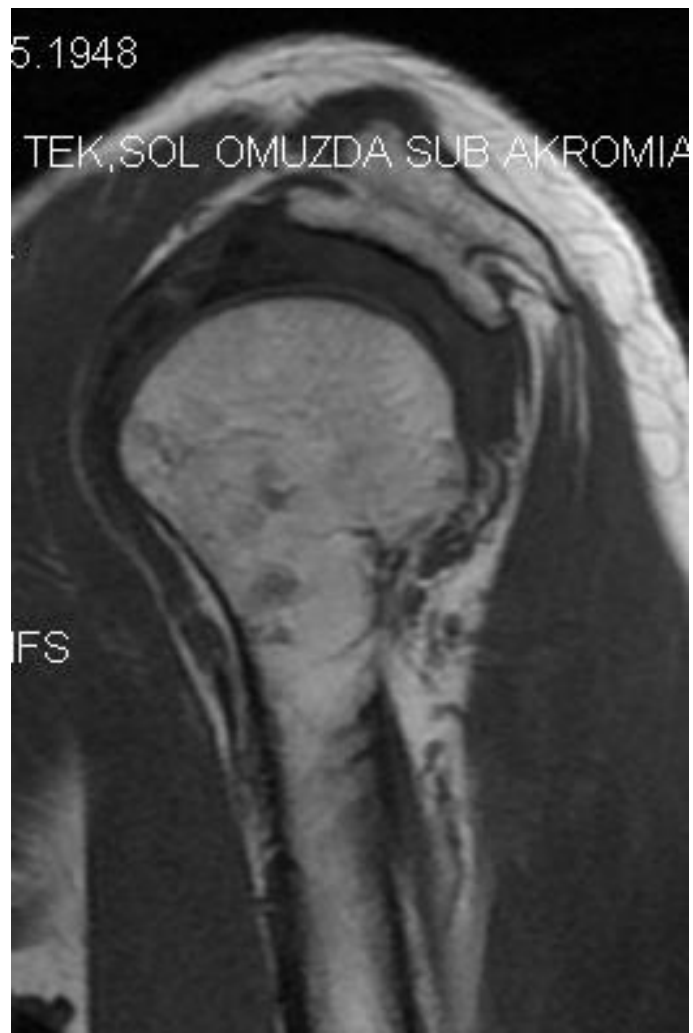

Şekil-1. Subakromial osteokondromun MRG koronal görüntüsü.

Başka bölgesinde benzer bulguya rastlanmayan hastada, değerlendirmeler sonucunda akromion distalposterior kısmına bağlı yaklaşık $1 \mathrm{~mm}$ kıkırdak şapka kalınlığı olan geniş pediküllü tekli osteokondrom ile uyumlu $15 \times 25 \times 40 \mathrm{~mm}$ boyutlarında kitle tespit edildi. Osteokondromun kemik iliği ile akromionun kemik iliği devamlılık göstermekteydi. Buna ek olarak, supraspinatus ve infraspinatus ortak tendonda tam kat rüptür tespit edildi. Kitlenin büyüklüğü nedeniyle artroskopik olarak çıkarılmasının oldukça zor olacağı düşünülerek mini açık transakromial yaklaşım tercih edilerek ameliyat edildi. Deltoid lifleri ayrıldıktan sonra kitle ortaya çıkarıldı. Eklem tarafında kıkırdak doku bulunan kitle görüldü ve pedikülü ile birlikte tek parça olarak eksize edildi. Subakromial dekompresyon yapıldı. Supraspinatus'un tamamının, infraspinatus'un ise kısmi tam kat rüptürününün tedavisi, 3 adet ankor kullanılarak çift sıra onarım şekline yapıldı. Patoloji raporu osteokondrom olarak bildirildi. Ameliyat sonrası 1. günde 30 derece abduksiyon yastığında dirsek ve el bileği egzersizleri başlanan hastaya kademeli olarak omuz egzersizleri verildi. Ameliyat sonrası 3. ayda hastanın ağrısında belirgin azalma mevcuttu. Aynı süre içinde, hastanın ameliyat edilen omzu tam eklem hareket açıklığına kavuştu. Ameliyat sonrası 19. ayına kadar olan izleminde, hastada rekürrens görülmedi.

Hastadan tıbbi verilerinin yayınlanabileceğine ilişkin yazılı onam belgesi alındı.

\section{Tartışma}

Rotator manşet rüptürünün subakromial osteokondroma bağlı geliştiğini bildirdiğimiz olgu, literatürde nadir bildirilen olgulardandır. Günlük ortopedi ve travmatoloji pratiğinde bu durumun nadir görülmekle birlikte akılda bulundurulmasının önemli olduğu kanaatindeyiz.

Osteokondromlar, bursite bağlı ağrı, kozmetik sorunlar, mekanik iritasyon, ya da çalışmamamızdaki hastada olduğu gibi rotator manşet rüptürü gibi durumlara sebep olmadığı sürece genellikle asemptomatiktirler ve asemptomatik oldukları sürece takip edilebilir, ağrılı durumlarda ise medikal tedavi desteği eklenebilir $(2,6)$. Genellikle uzun kemiklerin metafizlerinde görülmesiyle birlikte skapulanın en sık görülen benign tümörüdür (7). Skapular osteokondromlar çoğunlukla skapulanın ventral yüzeyinde görülür ve ağrılı bursit, skapular krepitasyon ya da skapular yalancı kanatlanmaya sebep olabilir $(8,9)$. Çalışmamızdaki hastada ise tablo, kanaatimizce mekanik iritasyon temelinde öncelikle omuz sıkışma sendromu ile başlamıştır. Sorunun kaynağının osteokondroma bağlı kitle olduğu tespit edilmeden medikal tedavi ve fizik tedavi gibi uygulamalarla kaybedilen zaman içinde durumun rotator manşet rüptürüne ilerlediğini düşünmekteyiz. $\mathrm{Bu}$ hususta hastaya hiç grafi çekilmemesinin de tedavideki gecikmeye etkisinin olduğu kanaatindeyiz. Skapular osteokondromun semptomatik tedavisinde başarı elde edilemezse tedavi total eksizyon olmalıdır (4). Literatürde genellikle açık eksizyon tercih edilse de artroskopi yardımlı eksizyon uygulanmış olgular da mevcuttur. Fukunaga ve ark. (9), skapular krepitasyona sebep olan bir subakromial osteokondromu artroskopi yardımlı eksize ettiklerini yayınlamışlardır. Çalışmalarında kitlenin boyutları $18 \times 15 \times 10 \mathrm{~mm}$ olarak, çalışmamızdaki kitlenin boyutlarının neredeyse beşte biri büyüklüğünde olduğunu bildirmişlerdir. Kitle küçüldükçe artroskopi yardımlı tekniklerin kullanılabilirliği de artmaktadır ancak bunun tam sınırı henüz kesin sınırlarla çizilememekle birlikte kitlenin lokalizasyonuna da bağlıdır. Bu bağlamda benzer bir çalışması olan Kumar ve ark. (4), skapulanın superomedial köşesinde kostal tarafta gelişen bir osteokondromun eksizyonunu lokalizayonunun riskli olması nedeniyle artroskopi yardımlı teknik kullanarak yapmışlardır. Rekürrens \%2 gibi nadir görülse de genellikle yetersiz eksizyona bağlıdır (10). Bu nedenle kitlenin pedikülü ile birlikte tamamının çıkarııması önemlidir. Çalışmamızdaki hastada da kitlenin tamamı pedikülü ile birlikte çıkarılmış 
ve erken dönemde değerlendirilmiş olsa da rekürrens görülmemiştir.

Sonuç olarak, subakromial alanda nadiren görülse de osteokondromlar rotator manşet rüptürüne sebep olabilmektedir. Tedavideki gecikmenin yırtığı genişleteceği unutulmamalı, erken total eksizyon ile tedavi edilmelidir.

\section{Kaynaklar}

1. Balke M, Schmidt C, Dedy N, Banerjee M, Bouillon B, Liem D. Correlation of acromial morphology with impingement syndrome and rotator cuff tears. Acta Orthop 2013;84(2):178-83.

2. Bigliani LU, Levine WN. Subacromial impingement syndrome. J Bone Joint Surg Am 1997;79(12):1854-68.

3. Frost NL, Parada SA, Manoso MW, Arrington E, Benfanti P. Scapular osteochondromas treated with surgical excision. Orthopedics 2010;33(11):804.

4. Kumar N, Ramakrishnan V, Johnson GV, Southern S. Endoscopically-assisted excision of scapular osteochondroma. Acta Orthop Scand 1999;70(4):394-6.

5. Citlak A, Akgün U, Bulut T, Aslan C, Mete BD, Sener M. Subacromial osteochondroma: A rare cause of impingement syndrome. Int J Surg Case Rep 2015;6(C): 126-8..

6. Neer CS II. Anterior acromioplasty for the chronic impingement syndrome in the shoulder: A preliminary report. J Bone Joint Surg Am 1972;54(1):41-50.

7. Cleeman E, Auerbach JD, Springfield DS. Tumors of the shoulder girdle: A review of 194 cases. J. Shoulder Elbow Surg 2005;14(5):460-5.

8. Fukunaga S, Futani H, Yoshiya S. Endoscopically assisted resection of a scapular osteochondroma causing snapping scapula syndrome. World J Surg Oncol 2007;22(5):37

9. Van Riet RP, Van Glabbeek F. Arthroscopic resection of a symptomatic snapping subscapular osteochondroma. Acta Orthop Belg 2007;73(2):252-4.

10. Unni KK. Osteochondroma. In: Unni KK (ed). Dahlin's Bone Tumors: General Aspects and Data on 11,087 Cases. 5th ed. Philadelphia: Lippincott-Raven; 1996:11-23. 